\title{
Alterations in carbohydrate composition of serum IgG from patients with rheumatoid arthritis and from pregnant women
}

\author{
J M PEKELHARING, ${ }^{1}$ ELLEN HEPP, ${ }^{2}$ J P KAMERLING,${ }^{3}$ G J GERWIG ${ }^{3}$ AND \\ B LEIJNSE
}

From the ${ }^{1}$ Department of Clinical Chemistry, Stichting Samenwerking Delftse Ziekenhuizen, PO Box 5010, 2600 GA Delft, The Netherlands; the ${ }^{2}$ Department of Biochemistry, Dr Daniel den Hoed Cancer Center, Rotterdam, The Netherlands; the ${ }^{3}$ Department of Bio-Organic Chemistry, Utrecht University, Utrecht, The Netherlands; and the ${ }^{4}$ Department of Chemical Pathology, Erasmus University, Rotterdam, The Netherlands

SUMmary The carbohydrate composition of IgG purified from serum of patients with rheumatoid arthritis (RA), pregnant women, and blood donors has been determined by gasliquid chromatography. Comparison of the results indicates that IgG from patients with RA contains significantly less galactose but more $N$-acetylglucosamine than normal IgG, whereas the fucose and sialic acid contents are not changed. The carbohydrate content of IgG in RA is reduced. IgG in pregnancy contains more galactose and more sialic acid than normal IgG, whereas fucose, $N$-acetylglucosamine, and the total carbohydrate content are not changed. These data suggest a temporal compensation of the RA associated undergalactosylation of IgG in female patients with RA during pregnancy, a period during which remission of the disease is often observed.

Key words: glycosylation, pregnancy.

Immunoglobulin $\mathrm{G}$ is a major plasma glycoprotein containing, on average, $2 \cdot 8 \mathrm{~N}$-linked carbohydrate chains per molecule. ${ }^{1}$ The carbohydrate chains consist of a variety of diantennary complex-type structures, some containing an extra 'intersecting' $\mathrm{N}$-acetylglucosamine or a fucose residue. ${ }^{12}$

The plasma of patients with rheumatoid arthritis (RA) contains aggregated immunoglobulins. ${ }^{2}$ These so-called 'immune complexes' differ from antigenantibody complexes in several ways. Because of the absence of antigen it is suggested that the aggregates consist of certain immunoglobulins with affinity for other immunoglobulins (autoantibodies). The strength of the interaction between the immunoglobulins $\left(\mathrm{Ka}=10^{5} \mathrm{l} / \mathrm{mol}\right)$ is less than that observed for normal antigen-antibody interactions, indicating that a different type of interaction may be involved. ${ }^{3}$

The recent finding of reduced galactosylation of

Accepted for publication 31 July 1987.

Correspondence to Dr J M Pekelharing. Department of Clinical Chemistry. Stichting Samenwerking Delftse Ziekenhuizen, PO Box 5010, 2600 GA Delft. The Netherlands. the diantennary carbohydrate chains of total IgG in patients with RA has led to a new hypothesis concerning the aggregation of IgG molecules. ${ }^{4}$ Less sugar constituents in the $N$-linked glycans of IgG could make IgG more 'sticky' owing to a lectin-like activity.

If incomplete glycosylation of $\operatorname{IgG}$ causes the formation of harmful IgG aggregates, then conditions inducing an increased plasma glycoprotein glycosylation, such as pregnancy, ${ }^{5}$ could reverse this aggregation. A decrease in $\mathrm{C} 1 \mathrm{q}$ binding activity has indeed been found in patients with RA during pregnancy, ${ }^{6}$ and a remission of RA during pregnancy is commonly observed,${ }^{78}$ indicating that the finding of an increased glycosylation of IgG during pregnancy would support the suggestion of a key role for the glycosylation of IgG in the pathogenesis of immune aggregates in rheumatoid arthritis.

The carbohydrate composition of IgG samples from the serum of pregnant women, patients with RA, and healthy blood donors was compared by detailed quantitative monosaccharide analysis with gas-liquid chromatography. 


\section{Materials and methods}

IS OLATION OF I g G

Blood samples were obtained from pregnant women, healthy blood donors, and from patients with active RA visiting the rheumatology polyclinics. Serum was extracted with an equal volume of n-hexane to remove lipids, and dialysed for 24 hours against $0 \cdot 0175 \mathrm{M}$ phosphate buffer, $\mathrm{pH} 6 \cdot 3$ (buffer A). After filtration, $2 \mathrm{ml}$ serum samples were applied to a column $(35 \times 2 \mathrm{~cm})$ of diethylaminoethylcellulose (DEAE) (Pharmacia, Uppsala, Sweden) equilibrated with buffer A. IgG, the unbound fraction, was eluted with buffer $\mathrm{A}$. The bound fraction was eluted with $0.4 \mathrm{M}$ phosphate buffer, pH $5 \cdot 2$, containing $2 \mathrm{M} \mathrm{NaCl}$, and discarded. The column was regenerated by washing with $0.25 \mathrm{M}$ phosphate buffer, pH 6.3, followed by buffer $\mathrm{A}$.

Table 1 Monosaccharide composition per three mannoses and percentage sugar of $\operatorname{Ig} G$ from 10 blood donors, nine patients with $R A$, and six pregnant women

\begin{tabular}{|c|c|c|c|c|c|c|}
\hline No & Man & $G l c N A c$ & Gal & NeuAc & Fuc & $\begin{array}{l}\text { Sugar } \\
(\%)\end{array}$ \\
\hline \multicolumn{7}{|c|}{ Blood donors } \\
\hline 1 & 3 & $3 \cdot() 9$ & 0.79 & 0.20 & $0 \cdot 70$ & 2.9 \\
\hline 2 & 3 & $3 \cdot 08$ & $1 \cdot 03$ & $0 \cdot 24$ & $0 \cdot 73$ & $2 \cdot 1$ \\
\hline 3 & 3 & $2 \cdot 94$ & 0.74 & $0 \cdot 14$ & 0.72 & $2 \cdot 1$ \\
\hline 4 & 3 & $3 \cdot 26$ & $0 \cdot 83$ & $0 \cdot 21$ & $0 \cdot 76$ & $2 \cdot 2$ \\
\hline 5 & 3 & $3 \cdot 29$ & $0 \cdot 87$ & $0 \cdot 16$ & 0.71 & $2 \cdot 4$ \\
\hline 6 & 3 & $3 \cdot 13$ & $0 \cdot 75$ & $0 \cdot 13$ & $0 \cdot 69$ & $2 \cdot 2$ \\
\hline 7 & 3 & $2 \cdot 93$ & $0 \cdot 82$ & $0 \cdot 22$ & $0 \cdot 67$ & $2 \cdot 5$ \\
\hline 8 & 3 & $3 \cdot 30$ & 0.93 & $0 \cdot 20$ & 0.77 & $3 \cdot 0$ \\
\hline 9 & 3 & $2 \cdot 91$ & $0 \cdot 71$ & $0 \cdot 18$ & $0 \cdot 66$ & $2 \cdot 3$ \\
\hline 10 & 3 & $3 \cdot(01$ & $0 \cdot 88$ & $0 \cdot 14$ & $0 \cdot 63$ & 1.9 \\
\hline Mean N & 3 & $3 \cdot() 9$ & $0 \cdot 84$ & $0 \cdot 18$ & $0 \cdot 70$ & $2 \cdot 36$ \\
\hline \multicolumn{7}{|c|}{ Patients with $R A$} \\
\hline 1 & 3 & $3 \cdot 50$ & $0 \cdot 61$ & $(0 \cdot 14$ & 0.73 & $2 \cdot 2$ \\
\hline 2 & 3 & $3 \cdot 30$ & 0.59 & $0 \cdot 20$ & 0.74 & $2 \cdot 2$ \\
\hline 3 & 3 & 3.49 & 0.59 & $0 \cdot 14$ & $0 \cdot 74$ & $2 \cdot 4$ \\
\hline 4 & 3 & $3 \cdot 24$ & $0 \cdot 57$ & 0.12 & 0.71 & $2 \cdot 0$ \\
\hline 5 & 3 & $3 \cdot 30$ & 0.58 & 0.14 & 0.72 & $2 \cdot 1$ \\
\hline 6 & 3 & $3 \cdot 19$ & $0 \cdot 62$ & ()$\cdot 11$ & $0 \cdot 68$ & $1 \cdot 8$ \\
\hline 7 & 3 & $3 \cdot 23$ & 0.92 & 0.28 & $0 \cdot 63$ & 1.9 \\
\hline 8 & 3 & $3 \cdot 24$ & 0.69 & $0 \cdot 13$ & $0 \cdot 78$ & $2 \cdot 0$ \\
\hline 9 & 3 & $3 \cdot 32$ & 0.88 & $0 \cdot 21$ & $0 \cdot 68$ & $1 \cdot 9$ \\
\hline Mean RA & 3 & $3 \cdot 31$ & $0 \cdot 67$ & $0 \cdot 16$ & $0 \cdot 71$ & $2 \cdot 06$ \\
\hline \multicolumn{7}{|c|}{ Pregnant women } \\
\hline 1 & 3 & $3 \cdot 23$ & 0.95 & $0 \cdot 26$ & $0 \cdot 84$ & $2 \cdot 1$ \\
\hline 2 & 3 & $3 \cdot 18$ & 0.98 & ()$\cdot 21$ & $0 \cdot 64$ & $3 \cdot 5$ \\
\hline 3 & 3 & $3 \cdot 15$ & $0 \cdot 77$ & $0 \cdot 23$ & 0.71 & $2 \cdot 1$ \\
\hline 4 & 3 & $3 \cdot 16$ & 0.96 & 0.22 & $0 \cdot 6.5$ & $2 \cdot 1$ \\
\hline 5 & 3 & $3 \cdot 14$ & $1 \cdot 10$ & $(0 \cdot 24$ & $0 \cdot 70$ & $2 \cdot 3$ \\
\hline 6 & 3 & $3 \cdot 17$ & 0.94 & $0 \cdot 23$ & $0 \cdot 70$ & $2 \cdot 3$ \\
\hline Mean P & 3 & $3 \cdot 17$ & 0.95 & $0 \cdot 23$ & 0.71 & $2 \cdot 40$ \\
\hline
\end{tabular}

Man=Mannose: GlcNAc $=N$-acctylglucosamine $; \quad G a l=$ galactose NeuAc $=N$-acetylneuraminic acid; Fuc $=$ fucose .
PURITY CHECK

Immunoelectrophoresis of the bound and the unbound fractions was carried out using a rabbit antiserum against human plasma proteins as well as specific rabbit antisera against $\operatorname{IgG}, \operatorname{IgA}$ and $\operatorname{IgM}$.

\section{SAMPLE PREPARATION}

The isolated $\mathrm{IgG}$ was dialysed against distilled watero for three days at $4^{\circ} \mathrm{C}$. The samples were then freezes dried and stored over $\mathrm{P}_{2} \mathrm{O}_{5}$ for 24 hours.

\section{MONOSACCHARIDE ANALYSIS}

Carbohydrate samples were subjected to methanolysis $\left(1.0 \mathrm{M} \text { methanolic } \mathrm{HCl}, 24 \text { hours, } 85^{\circ} \mathrm{C}\right)^{2}$ followed by gas-liquid chromatography of the trit methylsilylated ( $N$-reacetylated) methyl glycosides on a capillary CPsil5 WCOT fused silica columno (0.34 mm $\times 25 \mathrm{~m}$; Chrompack, Middelburg, Theo Netherlands). ${ }^{9}$

\section{Results}

Immunoelectrophoresis of the unbound fraction with rabbit antiserum against human IgG showed only one large precipitation arc in the IgG region.$\infty$ With antiserum against human plasma proteins other proteins were detected, in particular no Is and IgM were detected. The bound fraction was found to contain all other plasma proteins togethero with a small amount of IgG (slides not shown).

Table 2 Mean monosaccharide content (per 3 mannoses and sugar content $(\%)$, standard deviations and significance of the differences of $\operatorname{Ig} G$ from healthy blood donors $(n=10)$, patients with $R A(n=9)$, and pregnant women. $(n=6)$

\begin{tabular}{|c|c|c|c|}
\hline & Blood donors & Patients with $R A$ & $p$ Value \\
\hline GlcNAc & $3.09 \quad(0.15)^{*}$ & $3 \cdot 31 \quad(0 \cdot 11)$ & $<0 \cdot(01$ \\
\hline Gal & $0.84 \quad(0 \cdot 10)$ & $0.67 \quad(0 \cdot 13)$ & $<0 \cdot(05$ \\
\hline NeuAc & $0.18 \quad(0 \cdot 04)$ & $0 \cdot 16 \quad(0 \cdot 06)$ & $\mathrm{NS}+$ \\
\hline Fuc & $0.70 \quad(0 \cdot 04)$ & $0.71 \quad(0 \cdot 04)$ & NS \\
\hline \multirow[t]{2}{*}{ Sugar $(\%)$} & $2 \cdot 36 \quad(0 \cdot 35)$ & $2 \cdot 06 \quad(0 \cdot 19)$ & $<0 \cdot 05$ \\
\hline & Blood donors & \multicolumn{2}{|l|}{ Pregnant women } \\
\hline GlcNAc & $3.09 \quad(0 \cdot 15)$ & $3 \cdot 17 \quad(0 \cdot(03)$ & NS \\
\hline Gal & $0.84 \quad(0 \cdot 10)$ & $0.95 \quad(0.11)$ & $<0 \cdot 05$ \\
\hline NeuAc & $0 \cdot 18 \quad(0 \cdot 04)$ & $0.23 \quad(0.02)$ & $<0 \cdot 05$ \\
\hline Fuc & $0.70 \quad(0 \cdot(04)$ & $0.71 \quad(0.07)$ & NS \\
\hline \multirow[t]{2}{*}{ Sugar $(\%)$} & $2 \cdot 36 \quad(0 \cdot 35)$ & $2 \cdot 40 \quad(0 \cdot 55)$ & NS \\
\hline & Pregnant women & \multicolumn{2}{|c|}{ Patients with $R A$} \\
\hline GlcNAc & $3 \cdot 17 \quad(0 \cdot() 3)$ & $3 \cdot 31 \quad(0 \cdot 11)$ & $<() \cdot() 1$ \\
\hline Gal & $0.95 \quad(0.11)$ & $0.67 \quad(0 \cdot 13)$ & $<0 \cdot 01$ \\
\hline NeuAc & $0.23 \quad(0 \cdot() 2)$ & $0 \cdot 16 \quad(0 \cdot 06)$ & $<0) \cdot 05$ \\
\hline Fuc & $0.71 \quad(0.07)$ & $0.71 \quad(0.04)$ & NS \\
\hline Sugar $(\%)$ & $2.40 \quad(0.55)$ & $2 \cdot 06 \quad(0 \cdot 19)$ & NS \\
\hline
\end{tabular}

*Values are mean (SD).

†NS $=$ not significant. $\mathrm{p}>0$ ().(5): Mann-Whitncy test. 
The sugar analysis data of IgG obtained from 10 blood donors, nine patients with RA, and six pregnant women are given in Table 1 .

In Table 2 the significance of the differences of the mean monosaccharide and sugar contents is given, calculated with the Mann-Whitney test.

The IgG from patients with RA contained $20 \%$ less galactose than IgG from healthy subjects. The mean $\mathrm{N}$-acetylglucosamine content was increased by $20 \%$. The mean fucose and sialic acid contents were not different from normal. In pregnancy the mean galactose content was increased by $13 \%$ and the mean sialic acid content by $44 \%$, whereas $N$ acetylglucosamine and fucose contents were not different from normal.

\section{Discussion}

The monosaccharide analysis of IgG from patients with RA shows a significantly lower amount of galactose as compared with IgG from healthy individuals, whereas the $N$-acetylglucosamine content is significantly higher (Table 1). Although the analysis of carbohydrate content does not give information about the glycan structure, it is reasonable to assume that the major difference between IgG from patients with RA and from normals is the reduced galactosylation of the diantennary glycans, with a concomitant increase in $\mathrm{N}$-acetylglucosamine content. In an earlier study only the undergalactosylation was indicated. ${ }^{4}$ It was stated that there are no apparent changes in the levels of the $\beta-N$-acetylglucosaminyltransferase enzymes GnT I, GnT II, GnT III, and $\alpha(1 \rightarrow 6)$-fucosyltransferase. As only diantennary structures were detected ${ }^{4}$ the observed increase of $\mathrm{N}$-acetylglucosamine in this study has to be explained as a change in GnT III activity, responsible for the attachment of the intersecting $N$ acetylglucosamine. The presence of this sugar residue reduces the galactosylation of the mannose $\alpha(1 \rightarrow 3)$ arm by about $78 \% .{ }^{10}$ Thus if the $20 \%$ increase is of $N$-acetylglucosamine residues of the intersecting type, this would result in a decrease of galactose residues of about $16 \%$, comparable with the $20 \%$ that we found. Taken together, our results suggest a $20 \%$ increase in intersecting $N$-acetylglucosamine residues, resulting in undergalactosylation of IgG in patients with RA.

Using a solid phase lectin binding assay, others found that $\mathrm{IgG}$ from patients with $\mathrm{RA}$ bound significantly more to the immobilised plant lectins peanut agglutinin (PNA) and concanavalin A (con A) than IgG from normals. ${ }^{11}$

This indicates either an increased content or an increased availability of terminal galactose groups (binding to the PNA lectin) and diantennary sugar chains (binding to the con A lectin). As our results and those obtained by others ${ }^{4}$ indicate a decreased galactose content and suggest a decreased con A binding owing to the intersecting GlcNAc, a conformational change in the structure of $\operatorname{IgG}$ in patients with RA leading to increased lectin binding could explain these results. Indeed, an altered conformation of IgG in RA has recently been suggested. ${ }^{12}$

Our findings could support a viral aetiology of the disease. Viruses may alter the glycosylation of cell glycoproteins. ${ }^{13} 14$ If the IgG producing B cells are infected by a virus, for instance the RA associated Epstein-Barr virus, ${ }^{15}$ which has a preference for B lymphocytes, ${ }^{16}$ the result could be a modified glycosylation of IgG produced by the infected cells. This mechanism has been shown to occur in lymphoblastoid cells infected by influenza virus, where decreased glycoprotein sialylation takes place and is only partially compensated for by an increased cellular sialyltransferase. ${ }^{14}$ Another example is the polyoma virus transformation of baby hamster kidney cells, which induces a twofold increase in the activity of the enzyme GnT V that adds $N$-acetylglucosamine $\beta 1-6$ to the $\alpha 1-6$ linked mannose. ${ }^{17}$

If a reduced galactose content of IgG is a prerequisite for the appearance of (some of) the symptoms associated with RA, conditions of increased galactosylation could form a compensation and could be the basis of a therapeutic approach. Such a condition may exist for IgG during pregnancy or oestrogen therapy, two processes where an increased glycosylation of other plasma glycoproteins has been found. ${ }^{5}$

Our results show that a significant increase (13\%) of the galactose content of IgG occurs during pregnancy. The galactose content of IgG in pregnancy is $42 \%$ higher then in the RA group. Thus a partial compensation during pregnancy of the IgG undergalactosylation in female patients with RA can be imagined. IgG from one female patient with RA during pregnancy was analysed (results not shown). It contained high levels of galactose as found in the pregnancy group, and also high levels of $N$-acetylglucosamine as found in the RA group. Owing to the slight variation in carbohydrate analysis within each group this result has to be confirmed by carbohydrate analysis of IgG obtained from a larger number of pregnant women with RA.

Together with an increase of IgG galactose during pregnancy an increase of sialic acid is also found. This suggests a more complete glycosylation of the diantennary glycans of IgG during pregnancy. The $\mathrm{N}$-acetylglucosamine content of IgG during pregnancy is not different from normal.

Given the fact that the half life of IgG in the 
circulation is approximately three weeks, the recurrence of symptoms in female patients with RA a few weeks after delivery can also be explained, because the more galactosylated and sialylated IgG produced during pregnanicy will be gradually replaced by the RA associated undergalactosylated IgG with possible aggregating properties produced thereafter. Alternatively, the increased $N$-acetylglucosamine content of RA IgG could also have a role, but no decrease has been found to occur during pregnancy.

The changes in IgG glycosylation in pregnancy may be due to the altered hormonal state. Oestrogens $^{5} 18$ and prolactin ${ }^{19}$ do influence glycoprotein glycosylation. The association between autoimmune diseases such as RA and steroid hormones has been well described. ${ }^{2021}$ Oral contraceptives ${ }^{22} 23$ and the number of pregnancies ${ }^{24}$ have an influence as well. It is tempting to suggest the glycosylation of $\mathrm{IgG}$ as a key mediator in the occurrence of symptoms in RA.

Studies with asialylated IgG prepared in vitro underline the relation between the IgG glycosylation and rheumatoid factors. ${ }^{25} 26$ It would be of interest, in view of our results mentioned above, to extend these experiments with asialo-agalacto IgG prepared in vitro. Other studies have shown that differences in glycosylation of one Fab arm exist between precipitating and non-precipitating antibodies. $^{27} 28$ Thus the characteristics of IgG are delicately dependent on the glycosylation of the molecule.

The fact that remission of the symptoms often occurs in women with RA during pregnancy, together with our finding of an increase in IgG galactosylation in healthy pregnant women, supports the view ${ }^{4}$ that IgG glycosylation could have an important role in the disease. The carbohydrate analysis of IgG of female patients with RA during pregnancy and the investigation of aggregating characteristics of asialo-agalacto IgG prepared in vitro could clarify this point.

The support from Dr A J G Swaak, Dr J L Molenaar, Dr P Herbrink, and Mr G van der Knaap is gratefully acknowledged.

\section{References}

1 Mizuochi T, Taniguchi T, Shimizu A, Kobata A. Structural and numerical variations of the carbohydrate moiety of immunoglobulin G. J Immunol 1982; 129: 2016-20.

2 Rademacher T W, Dwek R A. Structural, functional and conformational analysis of immunoglobulin G-derived asparaginelinked oligosaccharides. Progress in Immunology 1983; 5: 95-112.

3 Mannik M, Nardella F A. IgG rheumatoid factors and selfassociation of these antibodies. Clin Rheum Dis 1985; 11: 551-72.

4 Parekh R B, Dwek R A, Sutton B J, et al. Association of rheumatoid arthritis and primary osteoarthritis with changes in the glycosylation pattern of total serum IgG. Nature 1985; 316: 452-7.
5 Raynes J. Variations in the relative proportions of microheterogeneous forms of plasma glycoproteins in pregnancy and disease. Biomed Pharmacother 1982; 36: 77-86.

6 Pope R M. Yoshinoya S. Rutstein J, Persellin R H. Effect of pregnancy on immune complexes and rheumatoid factors in patients with rheumatoid arthritis. Am J Med 1983; 74: 973-9.

7 Ostensen M. Aune B. Husby G. Effect of pregnancy and hormonal changes on the activity of rheumatoid arthritis. Scand J Rheumatol 1983; 12: 69-72.

8 Persellin R H. Cerere F. The interaction of pregnancy and the rheumatoid diseases. Clin Rheum Dis 1981; 7: 747-68.

9 Kamerling J P. Vliegenthart J F G. Gas-liquid chromatography and mass spectrometry of sialic acids. Cell Biology Monographs 1982; 10: $95-125$

10 Narasimhan S. Freed J C, Schachter H. Control of glycoprotein synthesis. Bovine milk UDPgalactose: $\mathrm{N}$-acetylglucosamine $\beta$ 4-galactosyltransferase catalyzes the preferential transfer of galactose to the GIcNAc $\beta 1,2$ Man $\alpha 1,3$-branch of both bisected and nonbisected complex biantennary asparagine-linked oligosaccharides. Biochemistry 1985; 24: 1694-700.

11 Malaise M G. Franchimont P. Bouillene C, Houssier C, Mahien $P$ R. Increased concanavalin A-binding capacity of immunoglobulin $\mathrm{G}$ purified from sera of patients with rheumatoid arthritis. Clin Exp Immunol 1987; 68: 543-51.

12 Hanson U B, Ohlin M, Lindstrom F D. IgG with a deviant conformation in serum and synovial fluid from rheumatoid arthritis patients. Scand J Immunol 1985; 22: 27-32.

13 Groen T P. Cell surface carbohydrate changes in rat kidney cell lines transformed by adenovirus type 5. Utrecht, Netherlands: Utrecht University, 1984. (Thesis.)

14 Duc Dodon M. Cecchelli R, Cacan R, Gazzolo L, Verbert to Viral neuraminidase and cellular ectosialyltransferase in hum: lymphoblastoid cells infected with influenza virus. Biochimk 1984; 66: 493-6.

15 Yao Q Y, Rickinson A B, Gaston J S H, Epstein M Disturbance of the Epstein-Barr virus-host balance in rheumatoid arthritis patients: a quantitative study. Clin Exp Immunol 1986; 64: 302-10.

16 Frade R, Barel M, Ehlin-Henriksson B, Klein G. gp 140, the C3d receptor of human B lymphocytes, is also the Epstein-Barr virus receptor. Proc Natl Acad Sci USA 1985; 82: 1490-3.

17 Yamashita K. Tachibana Y, Kobata A. Enzymatic basis for the structural changes of asparagine-linked sugar chains of membrane glycoproteins of baby hamster kidney cells induced by polyoma transformation. J Biol Chem 1985; 260: 3963-9.

18 Starr C M, Lucas J J. Regulation of dolichyl phosphatemediated protein glycosylation: estrogen effects on glycosyl transfers in oviduct membranes. Arch Biochem Biophys 1985; 237: 261-70.

19 Bradshaw J P, Hatton J, White D A. The hormonal control of protein $\mathrm{N}$-glycosylation in the developing rabbit mammary gland and its effect upon transferrin synthesis and secretion. Biochim Biophys Acta 1985; 847: 344-51.

20 Ahmed S A. Penhale W J, Talal N. Sex hormones, immune I responses, and autoimmune diseases. Mechanism of sex hormone action. Am J Pathol 1985; 121 : 531-51.

21 Masi A T, Josipovic D B, Jefferson W E. Low adrenal $\widetilde{\Omega}$ androgenic-anabolic steroids in women with rheumatoid arthritis: gas-liquid chromatographic studies of RA patients and matched normal control women indicating decreased 11-deoxy- $\omega$ 17 ketosteroid excretion. Semin Arthritis Rheum 1984; 14: 1-23.

22 Vandenbroucke J P. Valkenburg H A, Boersma J W, et al. Oral contraceptives and rheumatoid arthritis: further evidence for a preventive effect. Lancet 1982; ii: 839-42.

23 Vandenbroucke J P, Witteman J C M, Valkenburg H A, et al. $\stackrel{\mathscr{S}}{+}$ Non-contraceptive hormones and rheumatoid arthritis in perimenopausal and postmenopausal women. JAMA 1986; 255: 1299-303.

24 Silman A J. Is pregnancy a risk factor in the causation of $\varrho$ rheumatoid arthritis? Ann Rheum Dis 1986; 45: 1031-4. 
25 Duc Dodon M, Quash G A. The antigenicity of asialylated IgG: its relationship to rheumatoid factor. Immunology 1981; 42: 401-8.

26 Galloway G, Leung A Y T, Hunneyball I M, Stanworth D R. The successful use of asialylated IgG as an immunogen and arthritogen in the rabbit. Immunology 1983; 49: 511-8.

27 Leoni J, Labeta M, Margni R A. The asymmetric IgG non- precipitating antibody, localisation of the oligosaccharide involved, by concanavalin A interaction. Mol Immunol 1986; 23: $1397-400$.

28 Labeta M O, Margni R A, Leoni J, Binaghi R A. Structure of asymmetric non-precipitating antibody: presence of a carbohydrate residue in only one Fab region of the molecule. Immunology 1986; 57: 311-7. 